\title{
Simulation of the thermal state of the workpiece made of polymer-matrix composites using microwave radiation
}

\author{
Pavel Prosuntsov ${ }^{1, *}$, Sergey Reznik ${ }^{1}$, and Pavel Polsky ${ }^{1}$ \\ ${ }^{1}$ Bauman Moscow State University, Department of Rocket and Space Composite Structure, 105005 \\ Moscow, $2^{\text {nd }}$ Baumanskaya 5, Russia
}

\begin{abstract}
The simulation results of the thermal state of a cylindrical workpiece made of composite material and exposed to the action of microwave radiation are presented. The mathematical model of a workpiece allows the analysis of the interconnected thermal and electromagnetic processes in the equipment operating area, and also takes into account the exothermic effect associated with the curing of the polymer matrix.
\end{abstract}

\section{Introduction}

The state of the art in materials science is aimed at the development of advanced materials that satisfy a complex of different, often incompatible, requirements. Specific strength and stiffness are of the great importance in rocket production. On both these properties the polymer matrix composites (PMC) are beyond compare [1]. However, application of the PMC is limited by high cost of the manufacturing. In the PMC manufacturing the significant part of costs structure corresponds to the stage of matrix curing that is notable for long duration and high power consumption [2]. To reduce the cost of the PMC products the new methods of the materials processing should be adopted. One of the methods comprises application of microwave electromagnetic radiation for heating and curing the matrix in PMC. According to research led by Russian and foreign experts [3-13] the use of this method allows to reduce the power consumption of the products manufacturing via several times decrease of the thermal processing duration. Also, the products quality can be improved through increase of the temperature fields' uniformity in workpieces. It is expected that this technology will be more effective at manufacturing of the master parts of the composite structures (for instance, force rods of the flexible space reflectors, trusses and solar panels [14-20]).

A big series of studies dedicated to the technology development of the PMC curing was conducted in Bauman Moscow State Technical University [3-7]. Herewith in early studies the hypothesis for uniform distribution of the electromagnetic radiation energy in the operating area of the microwave heating equipment and workpiece was accepted.

*Corresponding author: pavel.prosuntsov@mail.ru 
In study [7] the model for analysis of the interconnected process of electromagnetic radiation transfer and workpiece heating of composite part is performed. It allowed estimating the influence of standing waves in operating area of the microwave heating equipment on the dynamics of the workpiece heating. Also, the changes in the structural layout of the equipment that enables to increase the workpiece heating uniformity were proposed. The result of this research showed that highly effective way to increase the workpiece heating uniformity made of PMC at microwave curing is its rotation around the transverse axis.

Among the foreign studies the paper [9] ought to be emphasized. In this study [9] a hexagonal chamber equipped with 12 radiation sources (magnetrons) symmetrically located around the axis of the chamber volume ( 2 magnetrons per side face) was used to heat a workpiece made of PMC by microwave radiation. Each magnetron in this equipment has a power of $850 \mathrm{~W}$ at a fixed frequency of $2.45 \mathrm{GHz}$. This design of the equipment provides a sufficiently high level of uniformity of the temperature field in the workpiece by the superposition of electromagnetic radiation from six different directions. Also, the successive activation of magnetrons leads to heating of various zones of the workpiece.

It should be noted that such important issue as the study of the completion degree dynamics of the matrix curing process under the action of microwave radiation has not been addressed. Accordingly, the analysis of the rational choice of the workpiece processing time has not been carried out. Also, the influence of the exothermic effect of the curing reaction of the matrix on the heating process has not yet been clarified.

\section{Object of study}

The object of study was cylindrical thin-walled workpiece made of PMC (reinforcement glass fiber, matrix - epoxy resin, volume fraction of the glass fiber was 0.5 ). The length of the workpiece was $250 \mathrm{~mm}$, the outer diameter - $25 \mathrm{~mm}$, the wall thickness $-12 \mathrm{~mm}$ (fig.1).

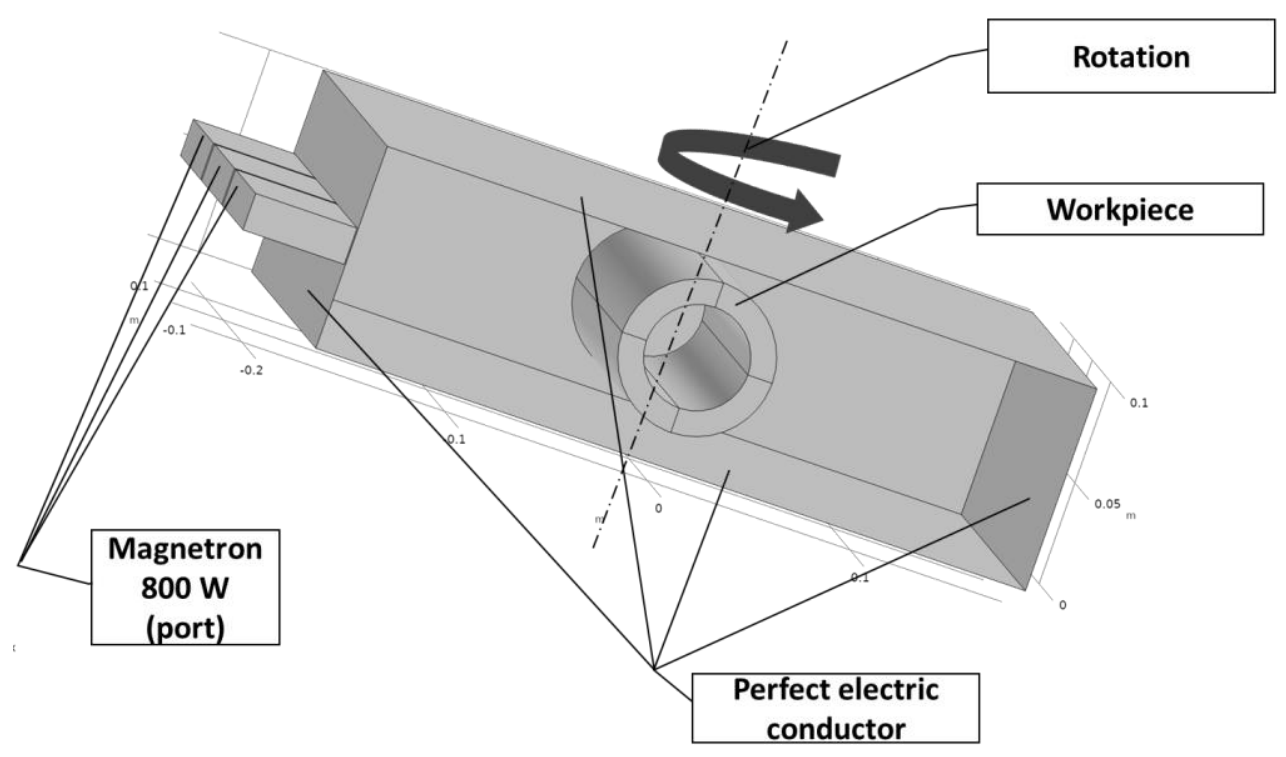

Fig. 1. A geometric model for the positioning of PMC workpiece in the operating area of a microwave heating equipment. 
The workpiece was located in the operating area of the microwave heating equipment that height was $100 \mathrm{~mm}$, width $-350 \mathrm{~mm}$ and length $-350 \mathrm{~mm}$. Three $800 \mathrm{~W}$ magnetrons that operated at a frequency of $2.45 \mathrm{GHz}$ were a heating source. During processing the workpiece rotated around its transverse vertical axis at a speed of $1 \mathrm{rpm}$.

It was assumed that the workpiece material has the following properties: density $2100 \mathrm{~kg} / \mathrm{m}^{3}$; thermal conductivity $0.41 \mathrm{~W} /(\mathrm{m} \cdot \mathrm{K})$; heat capacity $950 \mathrm{~J} /(\mathrm{kg} \cdot \mathrm{K})$; relative permittivity $4.75 \cdot(1-0.023 \cdot \mathrm{j})$; electrical conductivity 0 ; relative permeability 1 .

\section{Mathematical modelling of the processes in the equipment operating area}

\subsection{Simulation of the propagation of electromagnetic radiation in the equipment operating area}

The propagation of the electromagnetic wave in the operating area of a microwave heating equipment was described by Helmholtz equations:

$$
\begin{aligned}
& \nabla^{2} \mathbf{H}-\varepsilon \varepsilon_{0} \mu \mu_{0} \frac{\partial^{2} \mathbf{H}}{\partial \tau^{2}}=0 \\
& \nabla^{2} \mathbf{E}-\varepsilon \varepsilon_{0} \mu \mu_{0} \frac{\partial^{2} \mathbf{E}}{\partial \tau^{2}}=0,
\end{aligned}
$$

where $\mathbf{E}$ - electric field vector, $\mathrm{V} / \mathrm{m} ; \mathbf{H}$ - magnetic field vector, $\mathrm{A} / \mathrm{m} ; \varepsilon_{0}$ - permittivity, $\mathrm{F} / \mathrm{m} ; \mu_{0}$ - permeability, $\mathrm{H} / \mathrm{m} ; \varepsilon$ - relative permittivity; $\mu$ - relative permeability; $\tau$ time, s.

The following boundary conditions were satisfied at the interface between the internal volume of the chamber and the workpiece made of dielectric material:

$$
\begin{aligned}
& H_{\tau 1}=H_{\tau 2} ; \\
& E_{\tau 1}=E_{\tau 2} ; \\
& D_{\tau 1}=\frac{\varepsilon_{1}}{\varepsilon_{2}} D_{\tau 2} ; \\
& B_{\tau 1}=\frac{\mu_{1}}{\mu_{2}} B_{\tau 2},
\end{aligned}
$$

where $H_{\tau 1}$ and $H_{\tau 2}$ - tangent vectors of magnetic field strength in the chamber volume and workpiece; $E_{\tau 1}$ and $E_{\tau 2}$ - tangent vectors of electric field strength in the chamber volume and workpiece; $D_{\tau 1}$ and $D_{\tau 2}$ - tangent vectors of electric induction in the chamber volume and workpiece; $\varepsilon_{1}$ and $\varepsilon_{2}$ - dielectric constants in the chamber volume and workpiece; $B_{\tau 1}$ and $B_{\tau 2}$ - tangent vectors of magnetic induction constants in the chamber volume and workpiece; $\mu_{1}$ and $\mu_{2}$ - magnetic constants in the chamber volume and workpiece.

During the energy absorption of electromagnetic radiation, the heat generation inside the material took place. The intensity of the heat generation for dielectrics depends on the frequency and power of the radiation: 


$$
q_{m w}(T)=\varepsilon_{0} \varepsilon \operatorname{tg} \delta f E^{2}
$$

where $T$ - temperature, $\mathrm{K} ; f$ - linear frequency of the microwave radiation, $\mathrm{Hz} ; \operatorname{tg} \delta-$ dielectric dissipation factor.

The walls of the operating area were assumed as metal. Also, for these walls the perfect electric conductor condition was satisfied:

$$
E_{\tau}=0
$$

To study the magnetrons, the rectangular port model was used.

The process of the electromagnetic energy transfer in the equipment operating area was simulated for 7 workpiece positions. These positions corresponded to rotation angles of the workpiece around its transverse vertical axis $-0^{\circ}, 45^{\circ}, 90^{\circ}, 135^{\circ}, 180^{\circ}, 225^{\circ}$ and $270^{\circ}$.

\subsection{Simulation of the matrix curing in PMC}

It was assumed that the curing process of the matrix in PMC could be described by Arrhenius equation:

$$
\frac{\partial h}{\partial \tau}=-h^{a} \cdot(1-h)^{n} \cdot k \cdot \exp \left(-\frac{E}{R T}\right)
$$

where $h$-degree of matrix cure; $a, n$ - order of reaction; $k$ - preexponential factor, $1 / \mathrm{s} ; E-$ activation energy of the curing reaction, $\mathrm{J} / \mathrm{mol} ; R$ - gas constant, $\mathrm{J} /(\mathrm{K} \cdot \mathrm{mol})$. The initial degree of cure of the PMC workpiece was taken as 0 .

During matrix curing in the workpiece the volumetric heat generation took place with a power:

$$
q_{\text {exo }}(T)=\mathrm{v}_{m} \cdot \rho \cdot h^{a} \cdot(1-h)^{n} \cdot k \cdot \exp \left(-\frac{E}{R T}\right)
$$

where $q_{\text {exo }}-$ specific power of the exothermal effect of the matrix curing, $\mathrm{W} / \mathrm{m}^{3} ; \mathrm{v}_{m}-$ volume ratio of the matrix in the PMC; $\rho-\mathrm{PMC}$ density, $\mathrm{kg} / \mathrm{m}^{3}$.

\subsection{Heat transfer simulation in the PMC workpiece}

The three-dimensional transient non-linear process of the heat transfer in PMC workpiece that was exposed to microwave radiation was simulated. Also, in PMC workpiece the matrix curing with heat generation was occurred. Convective and radiation heat removal to ambient medium with constant temperature $T_{f}$ on each workpiece surfaces was considered. Also, mutual radiation of the surfaces in the internal cavity of cylindrical workpiece was taken into account. The magnetrons power in the curing process was time-dependent. At first stage the increase of the magnetrons power ensured rapid workpiece heating, but then their power decreased in order to limit the maximum temperature.

In this case the mathematical model of the heat transfer could be described by thermal conductivity equation:

$$
\begin{aligned}
& C \cdot \rho \frac{\partial T(r, z, \phi, \tau)}{\partial \tau}=\frac{\partial}{\partial z}\left(\lambda \frac{\partial T(r, z, \phi, \tau)}{\partial z}\right)+\frac{1}{r} \frac{\partial}{\partial r}\left(r \lambda \frac{\partial T(r, z, \phi, \tau)}{\partial r}\right)+ \\
& +\frac{1}{r^{2}} \frac{\partial}{\partial \phi}\left(\lambda \frac{\partial T(r, z, \phi, \tau)}{\partial \phi}\right)+q_{m w}(T)+q_{\text {exo }}(T)
\end{aligned}
$$


with initial condition:

$$
T=T_{0}
$$

and boundary condition on the workpiece surface:

$$
\vec{n} \cdot \lambda \frac{\partial T(R, z, \phi, \tau)}{\partial n}=\alpha_{f}\left(T \cdot(R, z, \phi, \tau)-T_{f}\right)+\varepsilon_{w} \sigma_{0}\left(T^{4}(R, z, \phi, \tau)-T_{f}^{4}\right),
$$

where $\varepsilon_{w}$ - workpiece emissivity factor; $\sigma_{0}$ - Stefan-Boltzmann constant, $\mathrm{W} /\left(\mathrm{m}^{2} \cdot \mathrm{K}^{4}\right) ; T_{f}$ - ambient temperature (wall of the operating area), $\mathrm{K} ; T_{0}$ - workpiece initial temperature, $\mathrm{K} ; \alpha_{f}-$ heat-transfer coefficient, $\mathrm{W} /\left(\mathrm{m}^{2} \cdot \mathrm{K}\right) ; \lambda$ - workpiece thermal conductivity, $\mathrm{W} /(\mathrm{m} \cdot \mathrm{K}) ; C$ - workpiece heat capacity, $\mathrm{J} /(\mathrm{kg} \cdot \mathrm{K}) ; \vec{n}$ - direction of the inward normal to a workpiece surface; $R, z, \phi$ - cylindrical coordinates.

\section{Modelling results}

\subsection{Simulation of the propagation of electromagnetic radiation in the equipment operating area}

The fig. 2 depicts the distribution of the electric field intensity in the operating area of the microwave heating equipment. The generation of standing waves that can lead to the heating nonuniformity is clearly visible.

\subsection{Simulation of the matrix curing in the PMC}

The fig. 3 illustrates the distribution of the degree of cure of the workpiece in the operating area of the microwave heating equipment. It can be concluded that the degree of cure initially grows only at individual points of the workpiece, then zones of cured material arise, which then merge with each other.

\subsection{Heat transfer simulation in the PMC workpiece}

The fig. 5 shows the change in temperature of the workpiece during microwave heating. The temperature at its individual points also increases nonuniformly, and its difference by the time the curing process is completed is about $50{ }^{\circ} \mathrm{C}$. The fig. 6 depicts the dynamics of temperature changes at control points of the workpiece. Local temperature peaks resulting from the exothermic effect of curing the binder are clearly visible.

\section{Conclusions}

1. The physical and mathematical models of the transfer of electromagnetic radiation in the operating area of the microwave curing equipment were developed.

2. The radiation field was simulated in the camera-magnetron-moving workpiece system and the role of standing waves arising in the operating area of the equipment was shown.

3. A physical and mathematical models were developed for the interconnected processes of heat transfer and matrix curing in the PMC preform, taking into account the exothermic effects of heat generation during matrix curing. 


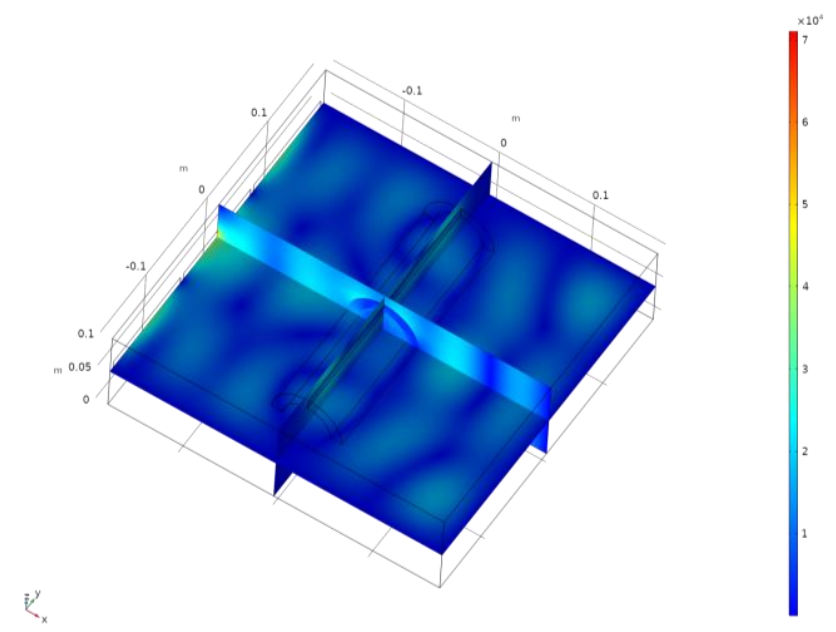

a)

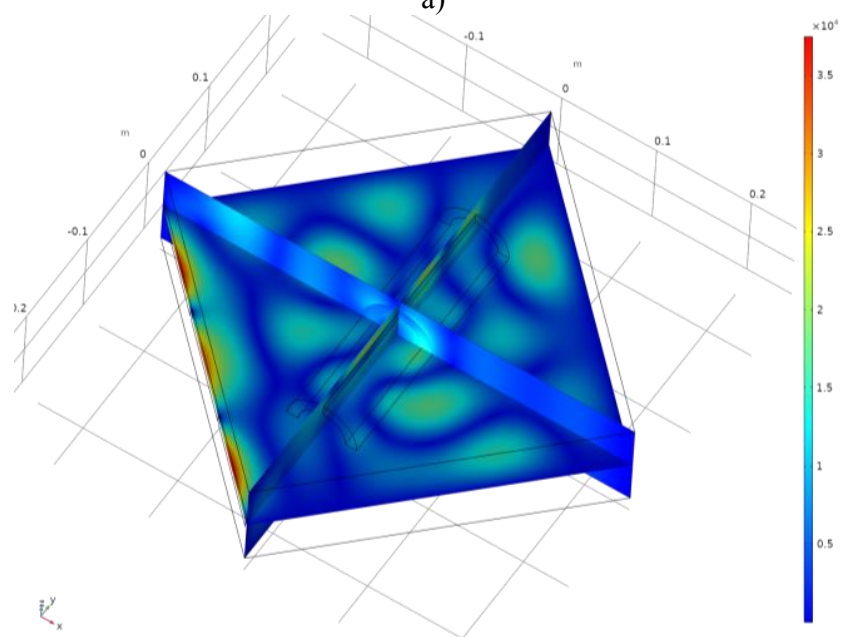

b)

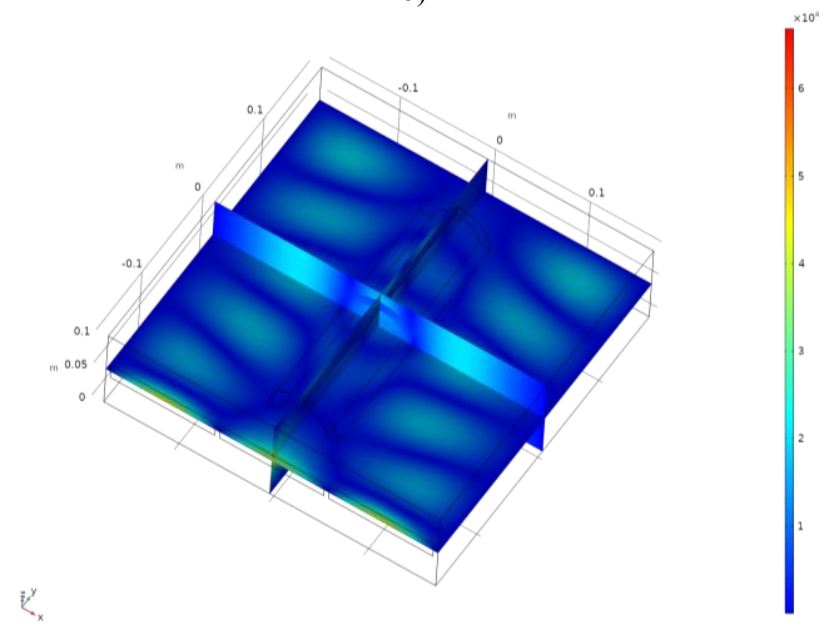

c)

Fig. 2. The electric field in the operating area of the equipment for the rotation angles of the workpiece 0 (a), 45 (b), 90 (c)degrees, $\mathrm{V} / \mathrm{m}$. 


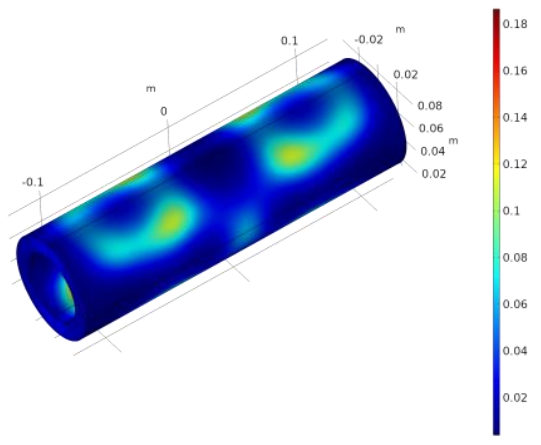

a)

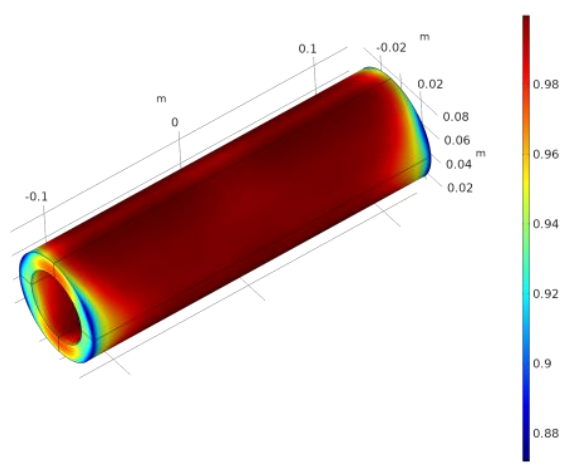

c)

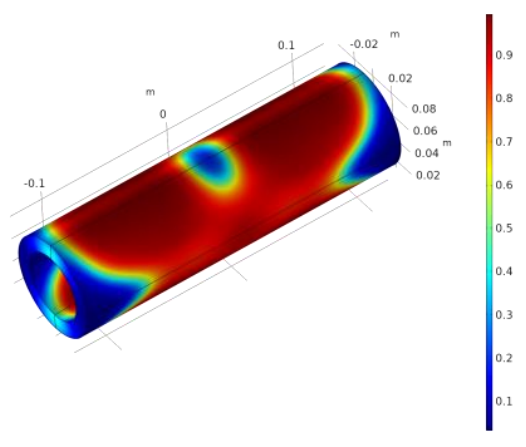

b)

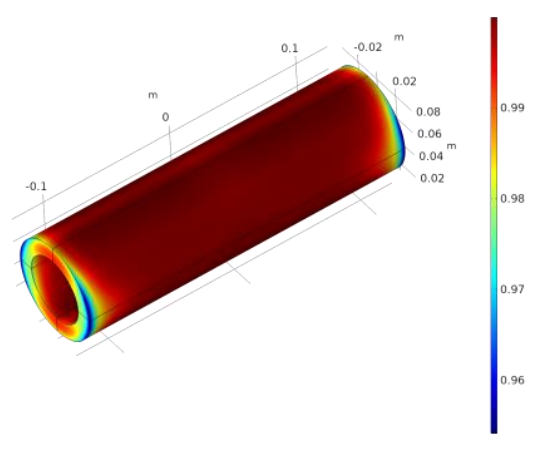

d)

Fig. 3. The degree of cure of the workpiece in the operating area of the microwave heating equipment at times 0.125 (a), 0.250 (b), 0.500 (c) and 1.000 (d) hour.

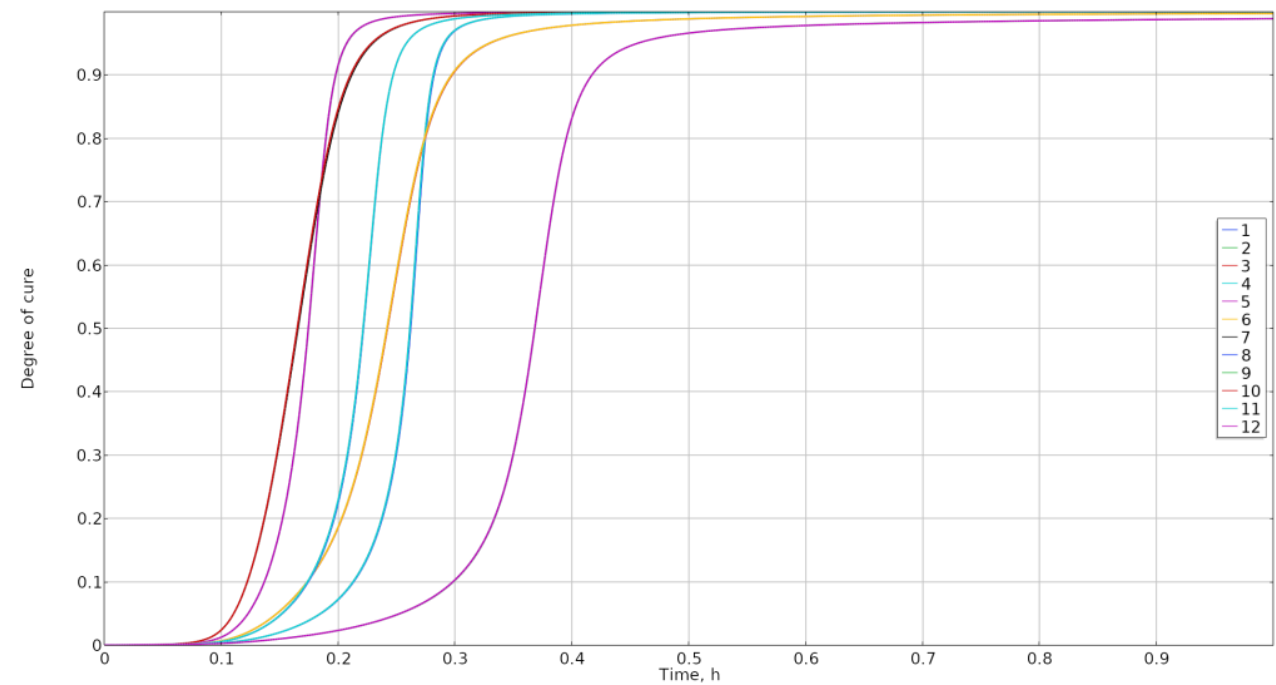

Fig. 4. The dynamics of the degree of cure at control points of the workpiece. Curves $1-3$ refer to the center, the middle and the top edges of the upper part of the workpiece respectively; curves 4-6 are the same for bottom part of the workpiece; curves 7-9 and 10-12 are the same for the left and right parts of the workpiece. 


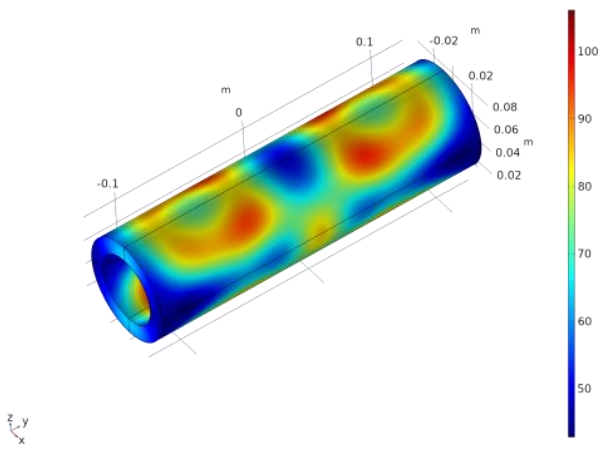

a)

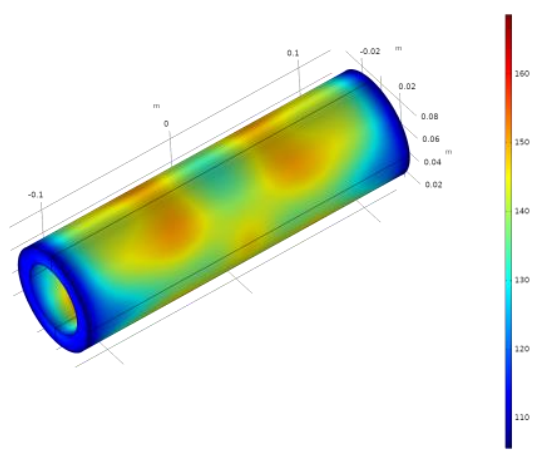

c)

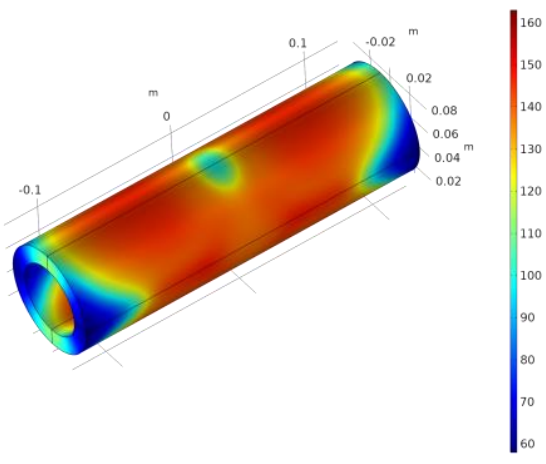

b)

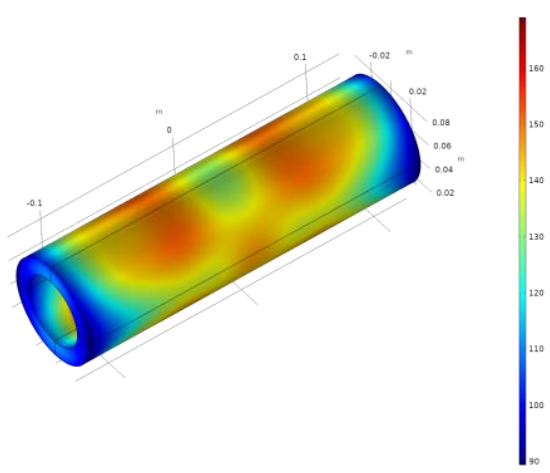

d)

Fig. 5. The temperature field of the workpiece in the operating area of the microwave heating equipment at times 0.125 (a), 0.250 (b), 0.500 (c) and 1.000 (d) hours.

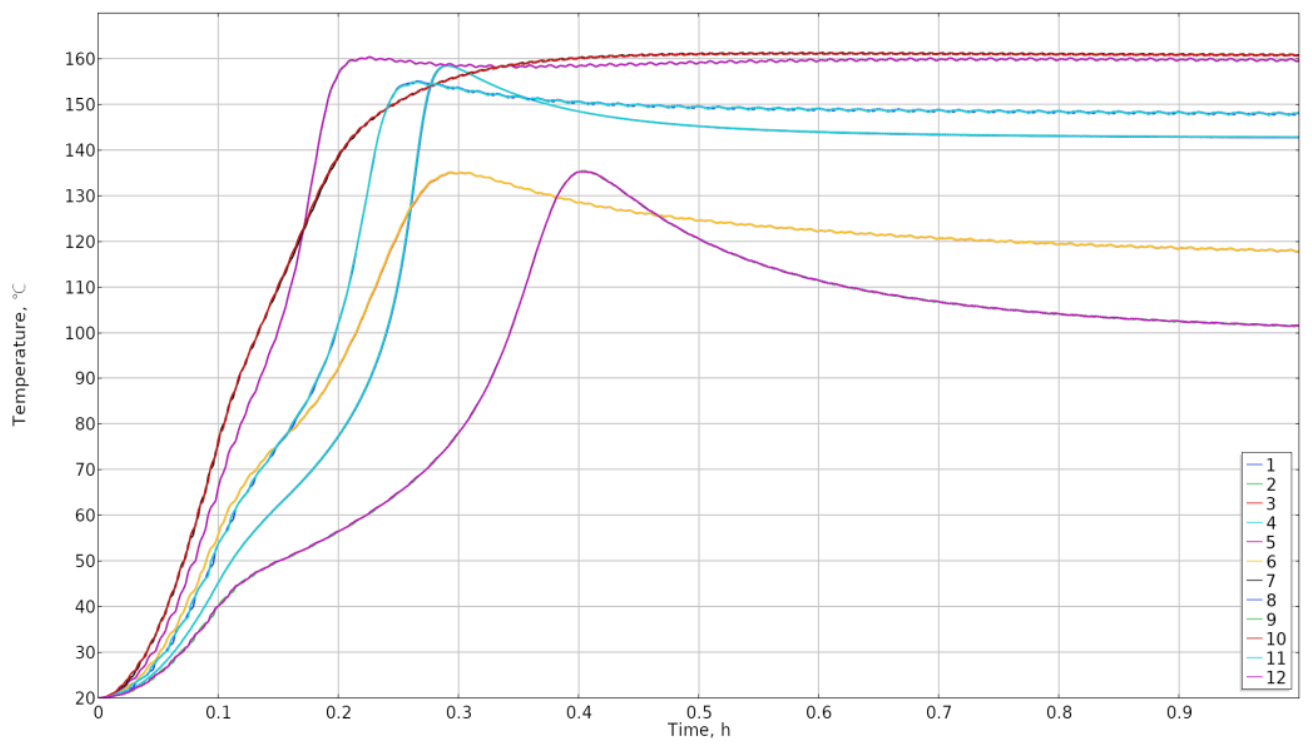

Fig. 6. The dynamics of temperature changes at control points of the workpiece, ${ }^{\circ} \mathrm{C}$. Legend corresponds to fig. 4 . 
4. Analysis of the results showed a significant role for the exothermic effects of heat generation during matrix curing and radiation heat removal from the workpiece surface.

5. The fundamental possibility of reduction of the processing time and power consumption in the manufacturing of PMC products using microwave curing was proved.

6. The use of microwave heating provides a high degree of uniformity of curing of the workpiece and improves the quality of the manufactured product.

The fig. 4 shows the dynamics of the degree of cure at the control points of the workpiece located above, below, to the left and to the right of its center in the vertical and horizontal planes. It is seen that the degree of cure reaches 0.96 in just 1 hour, which is significantly faster than with the traditional method of curing in an autoclave.

\section{References}

1. V. Vasilyev, Yu. Tarnopolsky, Kompozitsionnye materialy: Spravochnik [Composite Materials: Handbook] (Mashinostroyeniye, Moscow,1990)

2. I. Bulanov, V. Vorobey, Tekhnologiya raketnykh i aerokos-micheskikh konstruktsiy iz kompozitsionnykh materialov [Technology of rocket constructions of composite materials] (Bauman University Publishing House, Moscow, 1998)

3. K. Mikhailovskii, S. Reznik, A prediction of the temperature regimes binder curing of details from polymer composite materials by microwave radiation, Teplovie Processi $\mathrm{v}$ Technike, 6, pp. 363-368 (2014)

4. S. Reznik, S. Rumyantsev, Mathematical modelling of temperature state of cylinder details from polymer composite materials under microwave heating, Nauka i Obrazovanie, 1, pp. 6-21 (2014)

5. T. Guzeva Upgrade of the curing organic plastics technological regimes under microwave radiation. Thesis on Cand. of Sci (Bauman MSTU, Moscow, 2013)

6. T. Tsibizova, T. Guzeva, Automatic control systems for technological processes of curing products made of polymeric composites, Polymer Sci. D, 9(1), pp. 22-26 (2016)

7. P. Prosuntsov, S. Reznik, K. Mikhailovskii, E. Belenkov, Multiscale Modeling Of the Binder Polymer Composite Materials Heating Using Microwave Radiation, Journal of Physics: Conference Series. VII International Conference: Functional Nanomaterials and High Purity Substances, 1134(1), 012047 (2018)

8. G. Morozov, O. Morozov, A. Nasybullin, R. Sigmatullin, Microwave treatment thermoreactive and thermoplastic polymers Physics of Waves, Fizika Volnovikh Processov i Radiotekhnicheskie Sistemi, 3, pp. 114-121 (2011)

9. M. Kwak, Microwave curing of carbon-epoxy composites: process development and material evaluation (Imperial College London, London,2016)

10. D. Teufl, S. Zaremba, $2.45 \mathrm{GHz}$ microwave processing and its influence on glass fiber reinforced plastics. Materials, 11, no. article 838, (2018)

11. S. Das, A. Mukhopadhyay, S. Datta, D. Basu D., Prospects of microwave processing: An overview, Bulletin of Materials Science, 32(1), pp. 1-13 (2009)

12. R. Day, E. Samoladas, Micromechanics of model carbon epoxy composites cured using microwave heating, Science and Engineering of Composite Materials, 7(1-2), pp. 2326 (1998)

13. A. Navarrete, R. Mato, M. Cocero, A predictive approach in modeling and simulation of heat and mass transfer during microwave heating. Application to SFME of essential oil of Lavandin, Super Chemical Engineering Science, 68, pp. 192-201 (2012) 
14. V. Zimin, I. Koloskov, V. Meshkovsky,V. Usyukin, Investigation of natural oscillations for self-deployable truss space antennae, Trans. Mod. and Sim., 30, pp. 497-504 (2001)

15. A. Kotik, V. Usyukin, I. Vinogradov, M. Arkhipov, Simulation of reflecting surface deviations of centimeter-band parabolic space radiotelescope (SRT) with the large-size mirror, Proc. of SPIE - The Int. Soc. for Optical Engineering, 10567, 10567A (2017)

16. A. Meguro,S. Harada, M. Watanabe, Key technologies for high-accuracy large mesh antenna reflectors, Acta Astronautica, 53(11), pp. 899-908 (2003)

17. S. Reznik, V. Timoshenko, A. Shulyakovsky, O. Denisov, Thermal-vacuum tests of hollow composite rods intended for structures in space, Polymer Science D, 6(3), pp. 242-245 (2013)

18. S. Reznik, P. Prosuntsov, K. Mikhailovsky, I. Shafikova, Material science problems of building space antennas with a transformable reflector $100 \mathrm{~m}$ in diameter, IOP Conference Series: Materials Science and Engineering, 153(1), 012012 (2016)

19. R. Mironov, S. Reznik, R. Rukavishnikov, V. Shishulina, V. Zavaruev, Optical characterisation of metallic meshes for space antennas transformable reflectors, IOP Conference Series: Materials Science and Engineering, 153(1), 012013 (2016)

20. D. Golovatov, M. Mikhaylov, A. Bosov, Computational studies of connections of spatial composite structures of space-rocket techniques, Indian J. of Science and Technology, 9 (46), 107495 (2016) 